\title{
A SINTAXE DA LÍNGUA GERAL DE MINA NO CONTEXTO DA SINTAXE DAS LÍNGUAS GBE: PROBLEMATIZANDO HIPÓTESES DE REESTRUTURAÇÃO
}

\author{
Wellington Santos da SILVA ${ }^{1}$
}

\section{DOI: http://dx.doi.org/10.21165/gel.v18i3.3311}

Resumo: O objetivo deste trabalho é propor a análise de alguns tópicos da sintaxe da língua geral de Mina, uma língua africana falada em Minas Gerais, durante o século XVIII. A análise dos dados sintáticos, calcada na literatura sobre a gramática das línguas Kwa/ Gbe, serve para problematizar as abordagens de Yai (1997) e Bonvini (2008), os quais argumentam que a língua africana em questão passou por processos de reestruturação acentuada no Brasil. Porém, os tópicos gramaticais mostram que é possível dizer que a língua geral de Mina tem muitas semelhanças com as outras línguas Gbe, tanto do ponto de vista diacrônico quanto do ponto de vista das línguas Gbe modernas. Por tal razão, defendemos que ela não pode ser classificada como uma variedade crioulizada ou pidginizada.

Palavras-chave: língua geral de Mina. Línguas Gbe. Construções de Serialização Verbal. Verbos de Complementação Inerente.

1 Universidade Federal do Rio de Janeiro (UFRJ), Rio de Janeiro, Rio de Janeiro, Brasil; santosdasilvawellington@gmail.com; http://orcid.org/0000-0002-8502-8429 
- A sintaxe da língua geral de Mina no contexto da sintaxe das línguas Gbe: problematizando hipóteses de reestruturação

\title{
THE SYNTAX OF "LÍNGUA GERAL DE MINA" IN THE CONTEXT OF THE SYNTAX OF GBE LANGUAGES: CRITICISMS TO RESTRUCTURING HYPOTHESES
}

\begin{abstract}
This paper aims to analyze some topics of the syntax of "língua geral de Mina", an African language that was spoken in Minas Gerais during the 18th century. Based on the literature on Kwa/Gbe grammar, we analyze some syntactic data in order to criticize Yai's (1997) and Bonvini's (2008) proposals, who argue that "língua geral de Mina" underwent a noteworthy grammatical restructuring process. However, we submit that this African language has many similarities with other Gbe languages - modern and diachronic Gbe -, a reason why it cannot be classified as a creolized or pidginized variety.
\end{abstract}

Keywords: língua geral de Mina. Gbe languages. Serial Verb Constructions. Inherent Complement Verbs.

\section{Introdução}

Um dos aspectos mais salientes da história linguística brasileira consiste no contato estabelecido entre o português e várias línguas africanas, um dos frutos da terrível história colonial brasileira que, ao longo de mais de três séculos, levou vários povos africanos à travessia forçada do Atlântico. Não obstante as íntimas relações entre África e Brasil, houve, no campo dos estudos linguísticos, um longo período de negação do impacto das línguas africanas na formação do português do Brasil (doravante, PB). Porém, nos últimos anos, tem crescido o número de pesquisas que buscam desvendar os impactos dessas histórias de contato em vários domínios da gramática do PB, indo do léxico até a sintaxe.

Apesar do referido impulso dos estudos relativos aos impactos do contato linguístico na formação do PB, pouca atenção tem sido dada ao exame das línguas africanas que foram faladas no país. Em geral, parece ser dominante a concepção de que, no contexto colonial, os africanos escravizados rapidamente abandonavam suas línguas para fazer uso do português. Ora, conforme atestam várias pesquisas, é inegável a contribuição dos africanos escravizados para a formação e espraiamento do PB. Porém, parece-nos problemático não considerar que as línguas africanas propriamente ditas também compunham a ecologia de contato do Brasil colonial - no sentido de Mufwene $(2008)^{2}$-,

2 Em linhas bastante gerais, a ecologia linguística, na concepção de Mufwene (2008), diz respeito ao ambiente no qual se processam os fenômenos de evolução linguística, isto é, o nascimento, o desenvolvimento e a eventual morte de línguas, além dos contatos entre os seus falantes. Numa ecologia linguística, são considerados os fatores socioeconômicos estruturantes, aspectos sociais, históricos, políticos etc., bem como as línguas que entram em contato. Por isso, defendemos que a história linguística brasileira tem as línguas africanas como um dos seus eixos principais. 
visto que, de acordo com dados hauridos da historiografia, variedades oriundas de África serviram como meios de comunicação em diferentes pontos da colônia, como Minas Gerais, Rio de Janeiro e Bahia (cf. SOARES, 2019). Naturalmente, um elemento complicador para a abordagem desses aspectos da história linguística reside no fato de que é rara a existência de documentos que possibilitem a identificação das línguas africanas faladas no Brasil, ao contrário, por exemplo, das línguas gerais indígenas, que foram registradas pelos padres jesuítas. Entretanto, mesmo diante da pobreza de fontes, consideramos que alguns dos poucos documentos existentes não têm sido estudados a partir de critérios que possam realçar a relevância das línguas neles registradas para a compreensão do impacto do contato linguístico no Brasil.

Um dos documentos que podem ser inseridos no rol dos raros testemunhos sobre as línguas africanas no Brasil é a Obra Nova de Lingoa Geral de Mina, traduzida, ao nosso Igdioma, apresentada por António da Costa Peixoto, em 1741. Costa Peixoto era um homem português que, no século XVIII, desempenhava o cargo de juiz de vintena (cargo da Justiça não letrada) em São Bartolomeu, próximo ao distrito de Vila Rica de Ouro Preto - naquele momento, o epicentro da economia mineradora do Brasil colonial (ARAÚJO, 2013; SOUZA, 2004). No contexto da sociedade mineradora, Costa Peixoto mantinha sólidas interações com a comunidade dos africanos escravizados, tendo sido, inclusive, pai de quatro crianças mestiças, filhos de africanas Mina ${ }^{3}$. Devido a essa proximidade com o grupo dos africanos escravizados, na Obra Nova, Costa Peixoto apresenta uma espécie de manual de conversação na língua geral de Mina (doravante, LGM), composto de glossário e alguns diálogos na LGM, ambas as seções com traduções livres para o português.

É importante pontuar que a Obra Nova se constitui como um documento bastante diferente de outros encontrados no cenário colonial brasileiro, como as obras jesuíticas dedicadas às línguas gerais indígenas, como também a Arte da Lingoa de Angola (1697), gramática do quimbundo, escrita pelo jesuíta português Pedro Dias. A primeira diferença importante reside justamente na autoria do manuscrito, pois, diferentemente de outros, Costa Peixoto era um homem leigo (leia-se, não religioso), sem ambições de converter os africanos à religião cristã e que vivia imerso na densa comunidade dos desclassificados do ouro (cf. SANTOS DA SILVA, 2020; ARAÚJO, 2013)4. Além disso, diferentemente dos missionários, os quais detinham formação intelectual avançada para a época, Costa

3 De acordo com Parés (2018, p. 79), no século XVIII, o termo mina era utilizado para fazer referência aos africanos escravizados capturados na região da Costa da Mina, localidade que atualmente corresponde, aproximadamente, aos países de Gana, Togo e Benim.

4 Vale destacar que, segundo se registra em Araújo (2013), Costa Peixoto foi removido de seu cargo de juiz de vintena a pedido de pessoas ligadas aos agentes coloniais, devido às relações que ele mantinha com os africanos escravizados, sobretudo no ambiente das vendas. 
- A sintaxe da língua geral de Mina no contexto da sintaxe das línguas Gbe: problematizando hipóteses de reestruturação

Peixoto aparentava ser um homem modesto, de baixa instrução letrada. Segundo Fernandes (2012), embora apresentasse uma escrita razoável para a sua época, o autor da Obra Nova exibia variantes estigmatizadas do português. Vale destacar que o próprio Costa Peixoto tece comentários a respeito de sua baixa formação intelectual ao justificar a escrita da Obra Nova.

Dadas as razões apresentadas, entendemos que a Obra Nova não consiste numa gramática semelhante àquelas apresentadas pelos jesuítas. Aliás, de acordo com Rosa (2019), aqueles religiosos tinham como objetivo estudar os vernáculos locais encontrados tendo como base a gramática latina, sendo frequente o cotejo entre as variedades descritas e a língua clássica. Em Costa Peixoto (1741), pelo contrário, não há comparações com estruturas de outras línguas, muito menos com estruturas latinas. Aliás, segundo destacamos em Santos da Silva (2020), a Obra Nova não traz nenhuma descrição gramatical detalhada da LGM, mas apenas poucos comentários sobre questões pragmáticas, destinados a orientar a comunicação naquela língua. Assim, julgamos ser possível dizer que a Obra Nova não pode ser vista como uma gramática, mas sim como um manual de conversação, no qual, aparentemente, Costa Peixoto, homem em intenso contato com as redes de africanos escravizados, registrava as suas interações com os africanos mina ou as interações reportadas a ele.

O fato de Costa Peixoto não ter apresentado uma análise propriamente gramatical da LGM fez da Obra Nova uma incógnita para muitos estudiosos das línguas africanas, os quais procuraram especificar a língua que estava por detrás do rótulo língua geral. Esse trabalho de identificação da língua foi facilitado pelos dados oriundos das pesquisas historiográficas, nas quais se via que grande parte dos africanos escravizados que estavam nas Minas Gerais do século XVIII era oriunda da Costa da Mina, área de fala das línguas Gbe, variedades linguísticas caracterizadas por uma notável homogeneidade lexical e morfossintática, desde o século XVII (cf. ABOH, 2015a). Isso fez com que alguns linguistas identificassem a LGM com línguas Gbe atualmente faladas, como é o caso de Castro (2002), que define a LGM como o fongbe, língua falada no Benim. Entretanto, alguns estudiosos, como Yai (1997) e Bonvini (2008), analisaram a LGM como uma língua de contato, descrevendo-a como uma variedade em fase de crioulização ou como uma variedade pidginizada, concepções por nós classificadas como hipóteses de reestruturação acentuada, na medida em que defendem que a LGM, devido ao contato, se transforma, por assim dizer, numa língua com menos propriedades gramaticais ${ }^{5}$.

5 A concepção de crioulização e de pidiginização de ambos os autores será elucidada na análise crítica dos argumentos por eles apresentados, trabalho este realizado na próxima seção deste artigo. 
Neste trabalho, apresentamos uma perspectiva crítica às propostas de Yai (1997) e Bonvini (2008), sob o argumento de que a análise de tópicos da sintaxe da LGM coloca em xeque o entendimento dos autores supracitados sobre o impacto das ecologias de contato na trajetória das línguas. Neste sentido, o objetivo do trabalho não é arguir teoricamente os conceitos de pidgin e crioulo, mas sim mostrar que alguns tópicos da sintaxe da LGM mostram que tais classificações devem ser feitas com mais cautela. Assim, começamos por apresentar as visões de Yai (1997) e Bonvini (2008) sobre o papel que o contato linguístico teve na formação da LGM. Em seguida, apresentamos alguns aspectos gerais sobre a sintaxe das línguas Gbe, comparando-os aos traços exibidos pela LGM. Na sequência, apresentamos algumas considerações finais. No que diz respeito à metodologia do trabalho, informamos que os dados da LGM aqui analisados foram retirados da Obra Nova e, após a segmentação morfológica ${ }^{6}$, foi feita a análise sintática, com base em trabalhos representativos sobre a sintaxe das línguas Gbe.

\section{A língua geral de Mina e as línguas de contato: revisitando as abordagens de Yai (1997) e Bonvini (2008) ${ }^{7}$}

Conforme dissemos anteriormente, a configuração da Obra Nova fez da LGM uma incógnita para os estudiosos das línguas africanas, os quais, em diferentes trabalhos, procuraram vincular a variedade documentada por Costa Peixoto a uma das línguas Gbe modernamente faladas. Embora os vários trabalhos possam divergir quanto à identidade específica da LGM, um ponto comum entre eles é a observação de que, devido às condições estabelecidas num cenário de intenso contato linguístico, a variedade exposta na Obra Nova consiste numa língua, por assim dizer, diferenciada. Esta é a perspectiva, por exemplo, de Edmundo Correia Lopes, autor da primeira análise linguística conhecida da LGM, publicada em 1945, junto da edição da Obra Nova preparada pela Agência Geral das Colônias, sob o comando de Luís Silveira ${ }^{8}$. Nesse trabalho, Correia Lopes (1945) defende a hipótese de que a LGM seria uma variedade do gu, variedade esta, no entanto, modificada pelo uso de falantes, os quais, na visão de Lopes, estariam mais habituados à língua portuguesa:

\footnotetext{
$6 \mathrm{Na}$ grande maioria dos casos, os dados da Obra Nova vêm unidos, como se fossem, em termos leigos, uma só palavra. Por tal razão, foi feita uma segmentação morfológica.

7 A seguir, apresentamos a lista de glosas e abreviações utilizadas nos dados linguísticos analisados: NEG = Negação; TMA = Tempo, Modo e Aspecto; EXCL = Exclamação; SG = singular; POSS = possessivo; $A C C=$ acusativo; $\mathrm{MOOD}=$ modo; $\mathrm{NRL}=$ numeral; $\mathrm{V}_{\mathrm{ICV}}=$ inherent complement verb (verbo de complementação inerente); RED = reduplicação.

8 Vale destacar que uma primeira edição da obra foi feita pela Agência Geral das Colônias em 1944.
} 
- A sintaxe da língua geral de Mina no contexto da sintaxe das línguas Gbe: problematizando hipóteses de reestruturação

Em todo o caso, vê-se imediatamente que não se trata de uma mistura de línguas. Passando por muitas bocas em que não era senão hóspede, usada como meio de dissimulação por muitos escravos que falariam melhor o português, pode a linguagem africana ter perdido certo número de recursos próprios e, já por esse motivo, já, sobretudo, por influência do português, modificado pouco a pouco a sua sintaxe de posição, o seu vocabulário é na generalidade evəe e particularmente gu. (LOPES, 1945, p. 47).

Semelhantemente, podemos fazer referência ao trabalho de Castro (2002), no qual se assume com bastante clareza a hipótese de que a LGM seria, de fato, uma variedade de fongbe falada no Brasil. Porém, apesar da defesa dessa tese central, ao analisar o vocabulário da língua e atestar a presença de itens lexicais de outras variedades que não o fongbe - mais especificamente, do ewe, do gun, do mahi e do aizô -, Castro (2002) destaca que dados dessa natureza poderiam ser um reforço à proposta de Yai (1997), segundo o qual a LGM seria uma língua em fase de crioulização, resultante da mistura de variedades Gbe. Examinemos, pois, a proposta de Yai (1997).

De acordo com Yai (1997), a LGM seria o fongbe em fase de crioulização, processo que, de acordo com ele, seria comum nas Américas. É importante destacar que Yai (1997) não apresenta, de maneira explícita, o que ele entende por língua crioula e, consequentemente, pelo processo de crioulização. Entretanto, a interpretação do texto nos leva a argumentar que, no entendimento do intelectual beninense, a crioulização teria uma face linguística e outra cultural, e seria o reflexo da nativização de uma cultura Gbe diaspórica no Brasil ${ }^{9}$. De acordo com o autor, no Brasil, o fon teria servido como língua veicular para muitos falantes de diferentes etnias, pois devido ao histórico de conquistas do reino do Daomé no território da Costa da Mina ${ }^{10}$, os africanos escravizados das Minas Gerais teriam diferentes origens e diferentes línguas, tais como, o gungbe, o aladagbe, o mahi e até mesmo línguas Bantu, dada a referência que a Obra Nova fizera aos aglono. Para Yai (1997), esse cenário de contato entre diferentes etnias Gbe e não Gbe, as quais tomavam a LGM como uma língua franca, fazia do fongbe uma língua de estrutura variada. Uma prova disso, na visão do autor, estaria no léxico, no qual seriam percebidas palavras e estruturas gramaticais de diferentes línguas do continuum Gbe (YAI, 1997).

9 Remetemos o leitor ao capítulo 4 de Santos da Silva (2020), em que essa questão é discutida em maiores detalhes.

10 Neste ponto, Yai (1997) faz referência aos intensos conflitos travados nos reinos africanos de Alada e Daomé, que culminam com a vitória de Daomé, em 1724, através da tomada do controle da Costa dos Escravos e do tráfico transatlântico. O reino do Daomé, também conhecido como o reino Fon, tinha um perfil expansionista e travava intensas batalhas com os reinos vizinhos, sobretudo com Alada, seu principal antagonista (cf. $\mathrm{ABOH}$, 2015a). 
Outro argumento utilizado por Yai (1997) em defesa de sua hipótese de crioulização do fongbe diz respeito àquilo que Santos da Silva (2020, p. 164) interpretou como a "nativização de uma cultura Gbe diaspórica no Brasil". Assim, na perspectiva de Yai (1997), uma vez em solo brasileiro, os africanos Gbe, relacionados a outros povos, estavam formando uma nova comunidade, adaptand o conceitos trazidos de África a uma nova visão de mundo, qual seja, a visão do catolicismo europeu, que, em combinação com crenças africanas, parecia resultar num catolicismo, por assim dizer, hibrido, aspecto perceptível no léxico da LGM. Ora, a razão central para a configuração híbrida do catolicismo dos Gbe de Minas Gerais reside no fato de que, originalmente, os africanos escravizados oriundos da Costa da Mina cultuavam outras divindades, como Vòdú, Dàngbúi e Dàn (cf. $\mathrm{ABOH}$, 2015). Porém, uma vez cativos na colônia brasileira, muitos deles passaram a professar o catolicismo, evidenciando, no entanto, a permanência de algumas concepções religiosas pregressas. A fim de entendermos melhor essa questão, vejamos o comentário de Yai (1997) sobre a estratégia utilizada pelos Gbe para nomear Satanás, figura central no cristianismo, mas ausente na cosmovisão das religiões mais comuns na Costa da Mina:

Mas o conceito de Satanás ou deus do mal absoluto, da religião abraâmica, tão estranho e, na verdade, incompatível com sua visão de mundo africana, não poderia ter sido inteiramente compreendido em 1741. Um contato mais longo seria necessário. Não é surpreendente que os informantes de Peixoto tenham traduzido Satanás como Leba (Legba em fon), baseando sua tradução no "atributo de trapaceiro", comum a Satanás e a Legba, no qual Peixoto insistiu, assim como fizeram antes e depois dele todos os missionários cristãos. A linha de raciocínio é sustentada pelo fato de que os africanos encontraram traduções mais adequadas para Legba ao sincretizá-lo, no Brasil e em Cuba, com vários santos católicos e não com Satanás, quando eles alcançaram um melhor entendimento da doutrina cristã da visão de mundo judaico-cristã em geral. (YAI, 1997, p. 549, tradução nossa) $)^{11,12}$.

\footnotetext{
11 No original: "But the abrahamic religion concept of Satan or god of absolute evil, so strange, and indeed incompatible with their African worldview, could possibly not have been entirely grasped in 1741. A much longer contact would have been necessary. It is not surprising that the Peixoto's informants translated Satan as Leba (Legba in fon), basing their translation on the "trickster atribute" common to Satan and Legba, on which Peixoto must have insisted, as did before and after him all Christian missionaries. This line of reasoning is supported by the fact that Africans did find more adequate translations to Legba by syncretizing him, in Brazil and Cuba, with various Catholic saints and not Satan, when they did have a better understanding of the Christian doctrine and the judeo-christian worldview in general.".

12 Com efeito, de acordo com Castro (2004), na cosmovisão daqueles povos africanos, Legba seria uma espécie de mensageiro dos demais voduns, sendo caracterizado por sua capciosidade e ligação com a libido, mas não por ser a entidade representante do mal.
} 
- A sintaxe da língua geral de Mina no contexto da sintaxe das línguas Gbe: problematizando hipóteses de reestruturação

Assim como ocorre com as formas Leba/Legba, outros itens lexicais da LGM, destacados por Yai (1997), dão a dimensão da aproximação dos Gbe de Minas Gerais com o mundo católico do Brasil colonial. Alguns dos itens lexicais são apresentados a seguir:

(1) Avoduno (literalmente, homem de vodun) = "padre"

(2) Avoduchuhe (literalmente, casa de vodun) = "igreja"

(3) Avodumge (literalmente, colar de vodun) = "contas de rezar"

(4) hihavouvodum (literalmente, vodum de homem branco) $=$ "Nosso Senhor"

Ao analisar esses dados, Yai (1997) chama a atenção para dois aspectos importantes. O primeiro deles é que, assim como ocorrera no catecismo La Doctrina Christiana (1658), documento escrito por missionários capuchinos em visita ao reino de Alada, na Obra Nova, houve uma equiparação entre o conceito cristão de Deus e o conceito africano de vodum. Já o segundo aspecto destacado por Yai (1997) diz respeito ao dado em (4), pois enquanto em La Doctrina Christiana, um documento redigido em solo africano, Jesus havia sido equiparado a Lisa, uma divindade local, na LGM, uma nova palavra teria sido criada, demonstrando a vitalidade da língua na diáspora e a adaptação dos falantes aos conceitos formulados no catolicismo branco.

Deste modo, vemos que a hipótese de Yai (1997) acerca da crioulização do fongbe no Brasil é sustentada por dois eixos: de um lado, a LGM apresentaria palavras e estruturas gramaticais oriundas de diferentes variedades do continuum Gbe, devido ao seu uso como língua veicular; e de outro, o léxico da língua evidenciaria a formação de uma cultura Gbe diaspórica, diferente daquela deixada na Costa da Mina. Mais adiante, apresentamos uma problematização da tese de Yai (1997), mas antes observaremos a hipótese formulada por Bonvini (2008).

Emilio Bonvini apresenta uma breve e importante análise da LGM em seu texto Línguas africanas e português falado no Brasil (2008). Nela, o autor parte da ideia de que, no contexto colonial, a variedade documentada por Costa Peixoto servira de língua veicular, uma "solução econômica" para garantir a comunicação entre falantes de diferentes línguas, embora tipologicamente similares. O autor toma como base o trabalho de Lopes (1945), aqui citado anteriormente, no qual se defende a ideia de que a LGM, por ter sido utilizada como segunda língua e em um contexto de contato com o português, teria perdido alguns dos traços característicos das línguas africanas. Bonvini (2008), por sua vez, vai aprofundar essa análise, assumindo que, além de funcionar como uma língua veicular, no Brasil, a LGM estaria passando por uma fase de pidginização, no sentido de Manessy (1995): 
[...] Qual é, então, a verdadeira sintaxe da língua "mina" em relação ao português falado por Peixoto?

Esperando uma resposta a essas questões, mantemos nossa hipótese inicial [....], a saber, que a língua "mina" corresponderia a um falar veicular, mas acrescentando que, na verdade, este último se encontrava numa fase de pidginização (Manessy, 1995: 22-27), isto é, uma fase em que a língua estava submetida ao tríplice fenômeno de "adaptação" (= reinterpretação seguindo um modelo estrangeiro), de "simplificação" (= diminuição do número de manifestações externas dos mecanismos gramaticais e melhoria do seu rendimento funcional) e de "redução" (= redução a zero da complexidade do sistema linguístico). [...] (BONVINI, 2008, p. 45).

A teoria de Manessy (1995), utilizada por Bonvini (2008) para definir o conceito de pidginização, estabelece uma distinção entre língua natural e língua franca. Na perspectiva de Manessy (1995), uma língua natural seria aquela variedade adquirida como língua materna pelos falantes de uma determinada comunidade, ao passo que a língua franca seria uma variedade adquirida como segunda língua (L2) por indivíduos pertencentes a diferentes povos e usuários de diversas línguas maternas (L1). De acordo com Manessy (1995), as línguas francas seriam formadas através de um processo de perdas estruturais, tanto do ponto de vista do léxico quanto do ponto de vista da gramática. No âmbito da gramática, por exemplo, a formação de uma língua franca poderia levar ao desaparecimento dos contrastes gramaticais mais abstratos de uma língua natural, por exemplo, a oposição entre posse alienável e posse inalienável, marcada na estrutura de várias línguas do mundo.

Conforme vemos na citação, é a perspectiva de Manessy (1995) que Bonvini (2008) assume ao analisar a LGM, caracterizando-a como uma variedade linguística adaptada a um modelo estrangeiro - certamente, adaptada ao português -, de gramática simplificada e de sistema reduzido. É uma variedade dotada de tais características que o autor localiza na fase de pidginização. A esse respeito, notemos que Bonvini (2008, p. 45) identifica na LGM a ausência de uma série de propriedades gramaticais que, em sua visão, seriam características das línguas Gbe:

De outro lado, notar-se-á a ausência na língua "mina" de alguns fatos sintáticos que são característicos das línguas do grupo gbe: construções seriais dos verbos, nos quais cada verbo pode ser focalizado ou interrogado; construções clivadas do predicado; sintaxe de tipo alienável para as partes do corpo; emprego de pronomes logofóricos. [...] (BONVINI, 2008, p. 45). 
- A sintaxe da língua geral de Mina no contexto da sintaxe das línguas Gbe: problematizando hipóteses de reestruturação

Além das perdas estruturais que identifica na LGM, Bonvini (2008) questiona se a variedade documentada por Costa Peixoto estaria mais próxima das línguas Gbe ou do português, língua socioeconomicamente relevante na ecologia de contato das Minas Gerais do século XVIII. Ao tratar dessa questão, o autor analisa a construção negativa na Obra Nova, problematizando a proposta feita em Castro (2002). No trabalho de Castro (2002), é defendida a tese de que a LGM, encontrada no Brasil do século XVIII, seria equivalente ao fongbe, língua modernamente falada no Benim. Um dos argumentos centrais da proposta de Castro (2002) reside na análise do léxico da LGM, cuja maioria pertence ao fongbe, variedade esta que também deixou uma considerável herança no vocabulário litúrgico das religiões de matriz africana, sobretudo em terreiros localizados na Bahia e no Maranhão (cf. CASTRO, 2002). Assim, além da análise do léxico, Castro (2002) compara vários traços da gramática do fongbe àqueles encontrados na gramática da LGM, inclusive as construções negativas. Tal comparação é vista como problemática por Bonvini (2008), pela seguinte razão: o fongbe apresentaria dois tipos de construção negativa: o emprego do marcador negativo $\breve{a}$ no final de orações assertivas - entendida como marca canônica de negação no fongbe -, e o emprego da dupla negação $m a$... $\breve{a}$ em orações não assertivas (injuntivo-negativas; interrogativas; interrogativo-negativas). Já a LGM apresentaria os dois tipos de construção negativa expostos abaixo:

$\begin{array}{lll}\text { LGM }^{13} & & \\ \text { a. gam màtim } & & \\ \text { gam } \quad \text { mà } & \text { tim } & \\ \text { metal existir } & & \\ \text { "Metal não existe" } & & \\ \text { CP: "Não tenho a chave" } & \\ \text { b. nhimánum agamhã } & \\ \text { nhi ma num } & \text { agam } & \text { hã } \\ \text { 1SG NEG beber } & \text { álcool } & \text { NEG } \\ \text { "Eu não bebo álcool não" } & & \\ \text { CP: "Eu não bebo aguardente" } & \end{array}$

Na perspectiva de Bonvini (2008), as construções negativas encontradas na LGM - como as apresentadas em (5) - não corresponderiam, de fato, à sintaxe das negativas do fongbe, pois enquanto o documento de Costa Peixoto apresentava o morfema ma, o

13 Todos os dados da LGM foram retirados da análise feita em Santos da Silva (2020). Em relação à forma de apresentação dos exemplos, trazemos os seguintes esclarecimentos: na primeira linha, manteremos a grafia utilizada na edição de 1945 da Obra Nova; na segunda linha, apresentamos a segmentação dos morfemas; na terceira linha, introduziremos as respectivas glosas; na quarta linha, apresentamos a nossa tradução do exemplo, com base na literatura sobre as línguas Gbe; e, por fim, na quarta linha, apresentamos a tradução proposta por Costa Peixoto. 
marcador canônico de negativa do fongbe seria $\breve{a}$ - diga-se de passagem, um marcador não encontrado na LGM (cf. SANTOS DA SILVA, 2020) -, e enquanto a dupla negação seria restrita no fongbe, ela seria a construção negativa mais frequente na LGM. Assim, após comparar os dados da LGM com exemplos oriundos de outras línguas Gbe, Bonvini (2008) conclui que a sintaxe da negação da variedade documentada por Costa Peixoto não corresponderia ao padrão encontrado em nenhuma das outras línguas do grupo, estado de coisas que o leva à seguinte conclusão:

Põe-se então a questão de saber donde vem exatamente a construção sintática da negação da língua "mina" de Costa Peixoto, assim como seu recurso quase sistemático à dupla negação. Cabe mesmo perguntar-se se essa dupla negação não seria mais um "decalque" do português local da época. (BONVINI, 2008, p. 44).

Ora, se ao identificar a ausência de traços sintáticos característicos das línguas Gbe na LGM, Bonvini (2008) justificava sua análise sobre a língua - qual seja, uma variedade em fase de pidginização, posto que reduzida e simplificada - dentro da visão de Manessy (1995) -, ao sugerir que a dupla negação poderia ser um decalque do português, ele reforça a sua perspectiva, uma vez que a LGM seria, então, uma língua veicular "interpretada segundo um modelo estrangeiro", ou seja, o modelo do português ${ }^{14}$.

Entendemos que propostas como as de Yai (1997) e Bonvini (2008) podem ser problematizadas sob diferentes ângulos, sobretudo do ponto de vista das teorias sobre o contato linguístico e do ponto de vista das características mais gerais da sintaxe das línguas Gbe. Dada a natureza deste trabalho, daremos destaque ao segundo domínio de análise, a fim de privilegiar a abordagem por nós enunciada na introdução deste artigo: conhecer, na medida do possível, a estrutura das línguas africanas trazidas para o Brasil no período colonial. Assim, dado o potencial heurístico da Obra Nova, na próxima seção, analisaremos alguns tópicos da sintaxe da LGM no contexto da gramática das línguas Gbe, com o fito de mostrar que, diferentemente do que defendem Yai (1997) e Bonvini (2008), a variedade documentada por Costa Peixoto se aproxima muito das línguas Gbe da África Ocidental, não sendo caracterizada por perdas estruturais acentuadas.

14 Conforme indica um dos pareceristas anônimos deste artigo - a quem agradecemos pela importante observação -, a hipótese de Bonvini (2008) sobre a dupla negação da LGM ser um decalque do português também poderia ter sido analisada à luz de dados diacrônicos do português, dada a existência de muitos documentos setecentistas mineiros. Entretanto, em virtude do objetivo do artigo - qual seja, confrontar as análises de Bonvini com base nos próprios traços das línguas Gbe -, não adentramos nos documentos diacrônicos do português. Porém, vale destacar que pesquisas dessa natureza não estão fora de nossos horizontes, pois conforme sugerimos em Santos da Silva (2021), talvez seja possível dizer que, no caso da sintaxe da negação e de fenômenos relacionados à periferia esquerda da sentença, a LGM e o PB estivessem passando por mudanças concomitantes e paralelas. 
- A sintaxe da língua geral de Mina no contexto da sintaxe das línguas Gbe: problematizando hipóteses de reestruturação

\section{A sintaxe da língua geral de Mina no contexto das línguas Gbe}

Uma das mais importantes características das línguas Gbe é a sua homogeneidade estrutural, tanto do ponto de vista do léxico quanto do ponto de vista de sua gramática. Aliás, se levarmos em consideração os dados apresentados por Aboh (2015a), veremos que, desde o século XVII, as variedades faladas na antiga Costa da Mina apresentam traços linguísticos bastante semelhantes. É desse período que datam dois dos poucos documentos diacrônicos das línguas Gbe, a saber: o já referido catecismo La Doctrina Christiana (1658) - documento escrito por missionários capuchinhos que atuavam no reino de Alada - e a Grammaire Abrégée (1730), parte de um relato de viajantes escrito em francês e na língua falada em Uidá - região portuária da Costa da Mina, atual Benim -, destinado a servir de apoio a mercadores de escravos e médicos que compunham os navios negreiros. A comparação entre esses registros diacrônicos e as línguas Gbe modernas dá a dimensão da notável homogeneidade que caracteriza essas variedades, dada a similaridade entre as raízes lexicais, os marcadores pré-verbais de Tempo, Modo e Aspecto (TMA), as construções de serialização verbal, as interrogativas-WH etc.

Ora, diante desse cenário, chama a atenção a especificidade da Obra Nova de Lingoa Geral de Mina, pois, diferentemente de La Doctrina, da Grammaire Abrégée e, naturalmente, das línguas Gbe modernas, Costa Peixoto (1741) documenta uma língua africana da diáspora, utilizada numa ecologia de contato complexa, marcada pela presença do português e, aparentemente, de outras línguas africanas e indígenas. Neste sentido, cabe perguntar: a LGM, como uma língua da diáspora, também poderia funcionar como mais um argumento em defesa da homogeneidade estrutural das línguas Gbe ao longo dos séculos? Ou, por outro lado, seguindo hipóteses como as de Yai (1997) e Bonvini (2008), ela seria uma língua marcada por acentuada reestruturação ${ }^{15}$ - crioulização, para Yai, e pidginização, para Bonvini -, devido ao seu uso como língua veicular por falantes $\mathrm{L} 2$, em contato com o português? Neste trabalho, defendemos a ideia de que a análise da sintaxe da LGM nos conduz para algo mais próximo da primeira pergunta enunciada.

Uma das principais características da sintaxe das línguas Gbe é a ocorrência de estruturas de serialização verbal, as quais apresentam a estrutura exposta em (6):

$$
\begin{aligned}
& \text { Estrutura de Serialização Verbal }(A B O H, 2015, \text { p. 46) } \\
& \text { Sujeito }>T M A>V_{1}>\text { Objeto }>V_{2}>\text { Adjunto }
\end{aligned}
$$

15 Por reestruturação acentuada, nos referimos a hipóteses segundo as quais a LGM teria perdido suas características de língua Gbe no Brasil, sendo as hipóteses crioulização e a pidginização dois exemplos emblemáticos de tal perspectiva. 
De acordo com Aboh (2009, p. 5), nas construções de serialização verbal das línguas Gbe, os marcadores TMA devem ocorrer apenas no $V_{1}$, que é analisado como um verbo funcional, responsável pela codificação gramatical da sentença. $O \vee_{2^{\prime}}$ em contrapartida, é entendido como o verbo lexical, codificador do evento e atribuidor de papel temático aos argumentos $(\mathrm{ABOH}, 2009)$. Tese semelhante é apresentada em Awoyale (1988, p. 9), em que se defende que o $V_{1}$ de uma construção de serialização verbal é o responsável por expressar a modalidade, isto é, a maneira como o evento que o $\mathrm{V}_{2}$ codifica foi realizado. Para fundamentar sua análise, Aboh (2009) apresenta o seguinte exemplo do gungbe:

$$
\begin{aligned}
& \text { gungbe }(\mathrm{ABOH}, 2009 \text {, p. 24) })^{16} \\
& \text { Òjé Sć!sínú kùn mótò cè só! àdó } \\
& \text { EXCL. Sesinou dirigir carro 1SG.POSs bater muro } \\
& \text { "Sesinou dirigiu meu carro bateu o muro" } \\
& \text { "Sesinou bateu meu carro dirigindo" }
\end{aligned}
$$

Aboh (2009, p. 25) argumenta que, em exemplos como (7), a verdadeira tradução é a representada em itálico, uma vez que o $V_{1}$ da estrutura de serialização é um verbo funcional, ocupando um núcleo funcional CAUSA que caracteriza a eventualidade de "bater o carro". Neste sentido, o DP "mótò cè" recebe papel temático do verbo lexical "sb!". Deste modo, vê-se que a serialização verbal nas línguas Gbe é uma estrutura complexa, que envolve, dentre outras coisas, a combinação de um verbo funcional e de um verbo lexical ${ }^{17}$.

Assim como ocorre no gungbe moderno, outras variedades Gbe apresentam construções de serialização verbal, inclusive no Gbe diacrônico, mostrando, assim, que esse tipo de estrutura é pervasivo nesse grupo de línguas:

(8) Estruturas de serialização verbal nas línguas Gbe

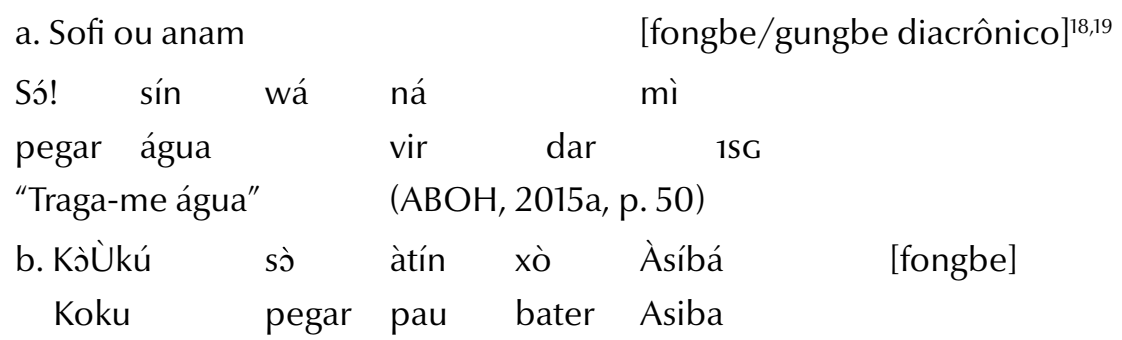

"Koku bateu em Asiba com um pau" ～(LEFEBVRE; BROUSSEAU, 2002, p. 415)

\footnotetext{
16 Nos exemplos retirados de textos em língua estrangeira, adaptamos as glosas e traduções para o português. 17 Para mais detalhes sobre a estrutura de serialização verbal, remetemos o leitor ao trabalho de Aboh (2009). 18 O exemplo (8a) foi retirado da Grammaire Abrégée (1730).

19 É importante esclarecer que Aboh (2015a), ao glosar o exemplo transcrito em (8a), atualiza a sentença para o gungbe moderno, padrão que repetimos aqui.
} 
- A sintaxe da língua geral de Mina no contexto da sintaxe das línguas Gbe: problematizando hipóteses de reestruturação

Mostrando a sua proximidade com as línguas Gbe, a LGM exibe construções de serialização verbal, algumas das quais são apresentadas em (9):

(9) LGM
a. sóvóname másusm

$\begin{array}{lllllr}\text { só } & \text { vó } & \text { na } & \text { me } & \text { má } & \text { susm } \\ \text { pegar } & \text { pano } & \text { dar } & \text { 1SG.ACC } & \text { 1SG.MOOD } & \text { limpar }\end{array}$
Lit: "Pegue pano dê-me deixe-me limpar"
CP: "De cá a toalha para me limpar"
b. máhichónumdu)
má hi chó num du)
1SG.MOOD ir comprar coisa comer
Lit: "Deixe-me ir comprar coisa comer"
CP: "Vou comprar alguma coisa para comer"
c. guigeroi cou sógam name
gui geroi cou só gam na me
2SG querer NRL pegar balança dar 1SG.ACC
Lit: "Você quer meia oitava pegue balança dê-me"
CP: "De cá a balança se quiseres meia oitava"

Os dados em (9) mostram que, diferentemente do que afirma Bonvini (2008, p. 45), a LGM apresenta sim estruturas de serialização verbal. E, no que diz respeito ao segundo fato relativo aos verbos seriais aludido por Bonvini (2008), qual seja, a possibilidade de focalização de cada um dos verbos, Ameka (2010), ao estudar as línguas Kwa - família a qual as línguas Gbe pertencem -, mostra que a focalização dos verbos nas construções seriais não se constitui como um fenômeno totalmente livre, pois embora as línguas tendam a permitir a focalização do $V_{1}$, nem todas aceitam a focalização do $V_{2}$. Deste modo, mais dados seriam necessários para concluir a qual tipo de língua Kwa/Gbe a LGM pertence, dados estes que não parecem estar disponíveis na Obra Nova, que não se configura como uma gramática da língua, mas sim como um manual de conversação no qual Costa Peixoto registrou as interações linguísticas de que participou ou aquelas que foram reportadas a ele - por exemplo, os embates entre escravizados fugidos e agentes coloniais.

Além das construções de serialização verbal, outro traço bastante característico da estrutura argumental das línguas Gbe é a existência dos chamados verbos de complementação inerente. Os $\mathrm{ICV}^{20}$ - assim chamados por causa da sigla inglesa

20 Algumas teorias analisam os verbos de complementação inerente como verbos leves, verbos funcionais, semanticamente esvaziados. Esse fato foi lembrado por um dos pareceristas anônimos, a quem agradecemos. Entretanto, tal perspectiva analítica não é ponto pacífico na literatura. Para uma discussão teórica aprofundada, remetemos o leitor à tese de Essegbey (1999). 
para inherent complement verbs - são verbos que, obrigatoriamente, devem tomar um complemento na sentença, argumento este que contribui para a especificação de seu significado (ESSEGBEY, 1999). Um fato que chama a atenção nesses verbos é que eles se combinam com diferentes argumentos e, quando seu complemento muda, muda também o seu significado, conforme ilustram os dados de Aboh (2015b):

\begin{tabular}{|c|c|c|}
\hline Verbo & + Nome complemento & + significado ICV \\
\hline dù & àxó 'dívida' & ter dívidas ou ir à falência \\
\hline & gbe! 'vida' & aproveitar \\
\hline & xwè 'ano' & celebrar/festejar \\
\hline & àdì 'veneno' & irritar-se \\
\hline & wìnyán 'vergonha' & estar envergonhado \\
\hline & gán 'chefe' & tornar-se chefe \\
\hline & yà 'dor' & sofrer \\
\hline
\end{tabular}

Conforme vemos nos dados em (10), o verbo dù, originalmente, o verbo "comer" em línguas como gungbe e fongbe, pode combinar-se a diferentes complementos, resultando em significados, à primeira vista, inesperados. Tal estado de coisas, que ocorre com inúmeras raízes verbais das línguas Gbe, levantou o seguinte questionamento por parte dos sintaticistas: o verbo de complementação inerente $\left(V_{I C V}\right)$ seria um verbo lexical, como todos os outros da língua, ou as sentenças desse tipo seriam construídas por elementos de outra natureza? Aboh (2015b) vai concluir que os $\mathrm{V}_{\text {Icvs }}$ são melhor analisados como verbos funcionais, que não atribuem papel temático de argumento interno. Em razão deste fato, na posição de complemento, podem aparecer os mais diferentes tipos de sintagmas nominais ${ }^{21}$. Ainda de acordo com Aboh (2015b), as construções com $V_{\text {Icvs }}$ são sensíveis a outros tipos de processos sintáticos, tais como: o complemento inerente não pode ser pronominalizado, pois, quando isso acontece, o significado ICV é perdido; diferentemente do que ocorre com os verbos lexicais, quando os $V_{\text {ICVs }}$ são focalizados, é o complemento inerente que deve se mover para a periferia esquerda da sentença, sendo que, em termos de significado, entende-se que a construção é focalizada, como vemos em (11):

21 Remetemos o leitor ao trabalho de Aboh (2015b), no qual o autor argumenta que, nas construções com $\mathrm{V}_{\text {ICVS'}}$ a seleção semântica do complemento - e, portanto, a atribuição de papel temático - é feita por um núcleo verbal nulo interno ao VP. 
- A sintaxe da língua geral de Mina no contexto da sintaxe das línguas Gbe: problematizando hipóteses de reestruturação

(11) gungbe $(\mathrm{ABOH}, 2015 \mathrm{~b}, \mathrm{p} .14)$
a. Félé
tún
tán.
Fele
$\mathrm{V}_{\text {LBERAR }}$
saliva
"Fele cuspiu"
$\begin{array}{llll}\text { b. Tán } & \text { weÙ } & \text { Félé } & \text { tún. } \\ \text { saliva } & \text { FOC } & \text { Fele } & \mathrm{V}_{\text {LBERAR }}\end{array}$
'Fele CUSPIU'

Dadas as características aqui observadas, vê-se que os verbos de complementação inerente constituem uma estrutura de derivação complexa nas línguas Gbe e aparecem de maneira pervasiva nessas variedades linguísticas. Conforme indicamos em Santos da Silva (2020), a LGM também apresenta um considerável número de $\mathrm{V}_{\text {ICVS' }}$ alguns dos quais são apresentados em (12):

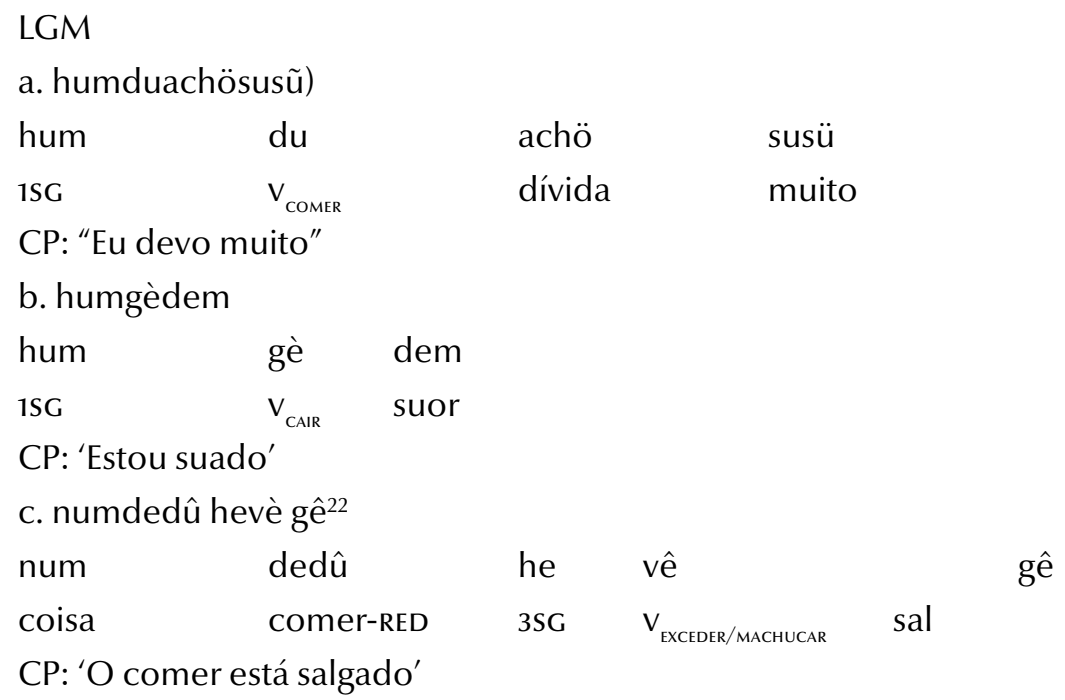

Os exemplos em (12), além de outros $V_{\text {ICvS }}$ que Santos da Silva (2020) descreve na LGM, constituem em mais um argumento para aproximar a língua documentada por Costa Peixoto (1741) das demais variedades Gbe, refutando, portanto, teses sobre sua reestruturação acentuada. Aliás, o fato de Costa Peixoto traduzir o sentido da construção ICV, e não proceder a uma tradução literal, é uma prova de que seus informantes - ou até mesmo Costa Peixoto - sabiam tanto a LGM, variedade Gbe da diáspora, quanto o português, dada a facilidade de verter para a língua românica uma estrutura tão diferente.

22 Segundo vemos em Aboh (2007), nas línguas Gbe, a reduplicação pode ser utilizada para transformar verbos em adjetivos. Assim, neste caso, temos em (12c) algo como "coisa comestível", que Costa Peixoto traduz como "o comer". Embora a LGM apresente outros casos de reduplicação, não adentraremos nesta questão aqui. Para mais detalhes sobre esse fenômeno na LGM, remetemos o leitor à tese de Santos da Silva (2020). 
Por fim, é necessário tratar rapidamente da construção negativa da LGM. Conforme vimos na seção anterior, Bonvini (2008) não encontra paralelo entre a dupla negação da LGM e as construções negativas das outras línguas Gbe, acabando por concluir que Peixoto registrara um decalque do português. Entretanto, quando olhamos para trabalhos sobre a sintaxe das línguas Gbe, vemos que elas apresentam três diferentes padrões de construção negativa, a saber:

(13) Sintaxe da negação em Gbe (ABOH; ESSEGBEY, 2010, p. 44)

\begin{tabular}{|c|c|c|c|c|c|}
\hline a. Súrù & má & dù & & nú & [gungbe] \\
\hline Suru & NEG & comer & & coisa & \\
\hline \multicolumn{6}{|c|}{ 'Suru não comeu' } \\
\hline b. Súrù & dù & & nú & á & [fongbe] \\
\hline Suru & comer & & coisa & NEG & \\
\hline \multicolumn{6}{|c|}{ 'Suru não comeu' } \\
\hline c. Súrù & mú & dù & nú & ò & [gengbe] \\
\hline Suru & NEG & comer & coisa & NEG & \\
\hline
\end{tabular}

Não obstante as línguas Gbe serem notavelmente semelhantes no léxico e na gramática, o grande ponto de divergência entre elas é exatamente na sintaxe da negação. Assim, as línguas de tipo-gungbe só apresentam a negação pré-verbal; as línguas do tipo-gengbe só apresentam a dupla negação; já as línguas do tipo-fongbe apresentam prototipicamente a negação com marcador no final da sentença e, em alguns casos restritos - como na oração condicional -, apresentam a dupla negação. Já a LGM apresenta dois padrões diferentes de construção negativa, como mostram os dados em (5), repetidos aqui como (14):

a. gam màtim
gam mà $\quad$ tim
metal NEG existir
"Metal não existe"
CP: "Não tenho a chave"
b. nhimátim a sim ruchuhẽ) hã
nhi ma num agam
1SG NEG beber álcool
"Eu não bebo álcool não"
CP: "Eu não bebo aguardente"


- A sintaxe da língua geral de Mina no contexto da sintaxe das línguas Gbe: problematizando hipóteses de reestruturação

Com efeito, se observarmos as restrições da sintaxe da negação nas línguas Gbe, vemos que a LGM parece apresentar, sim, uma mudança, pois enquanto as línguas africanas desse grupo se diferenciam entre si, cada uma apresentando um padrão, a LGM exibe dois tipos diferentes de negação, sendo mais frequente a dupla negação. Porém, diferentemente do que diz Bonvini (2008), tal comportamento não é completamente estranho às demais variedades Gbe, visto que a dupla negação é generalizada nas línguas de tipo-gengbe, e a negação pré-verbal generalizada nas línguas de tipo-gungbe. Neste sentido, é preciso ter cautela ao se falar que a dupla negação da LGM seria um decalque do português, até porque, perspectivas como a de Teixeira de Sousa (2018) defendem uma hipótese inversa, qual seja, a influência das línguas Gbe para o desenvolvimento de um tipo de dupla negação no PB. Portanto, em nossa perspectiva, cremos ser esta uma questão ainda não resolvida, havendo até mesmo a hipótese de que ambas, LGM (língua Gbe da diáspora) e português, estivessem passando por mudanças simultâneas na mesma direção, devido à ecologia de contato, hipótese esta sugerida por nós em Santos da Silva (2021). Seja qual for a resposta, o importante é pontuar que a sintaxe da negação da LGM revela padrões que, de alguma maneira, estão presentes no Gbe moderno, fato que, mais uma vez, não conduz a uma análise da língua documentada por Peixoto como uma variedade pidginizada, como o faz Bonvini (2008).

Ao longo desta seção, problematizamos em mais detalhes algumas das concepções trazidas por Bonvini (2008). Entretanto, cremos que, indiretamente, a análise que propusemos aponta algumas questões para o trabalho de Yai (1997), segundo o qual a LGM seria uma variedade em fase de crioulização justamente pelo fato de apresentar palavras e estruturas gramaticais de outras variedades do continuum Gbe, que não o fon, e também por evidenciar, em seu léxico, a emergência de uma espécie de cultura crioula. Ora, entendemos que, com relação a este último aspecto, a hipótese de Yai (1997) é bastante relevante e merece ser melhor estudada, através de um trabalho focado no léxico e na morfologia da LGM, algo que foge ao escopo da proposta feita aqui. Porém, em relação ao primeiro aspecto, ou seja, o da mistura de palavras e estruturas de outras línguas Gbe, argumentamos que um dos principais fatos evidenciados pela literatura é que as línguas Gbe, em seu conjunto, apresentam inúmeras semelhanças entre si, tanto na gramática quanto no léxico, sendo que, na gramática, a negação é um dos poucos pontos em que se nota uma divergência mais aparente. Neste sentido, não parece plausível assumir que, por exemplo, uma construção de serialização verbal ou um verbo de complementação inerente é do fongbe ou do gungbe, visto que todas elas apresentam o mesmo tipo de estrutura. Aliás, cabe acrescentar que, tal qual analisamos em Santos da Silva (2020) - com amparo de uma sólida literatura sobre a sintaxe das línguas Gbe -, a homogeneidade estrutural das línguas Gbe se faz notar em outros pontos da gramática da LGM, tais como: 
marcadores de TMA; interrogativas- $\mathrm{WH}$; sintaxe dos adjetivos predicativos e dos adjetivos atributivos; estruturas de Tópico e Foco. Deste modo, o argumento de que a LGM é uma língua em fase de crioulização devido à sua estrutura supostamente misturada ou a uma pretensa estrutura simplificada não se sustenta.

\section{Considerações finais}

Neste trabalho, procuramos apontar a necessidade de se analisar de maneira mais aprofundada os poucos documentos restantes que dão notícia das línguas africanas faladas no Brasil colonial. Conforme dissemos, por muito tempo, a própria hipótese da influência do contato não foi considerada pelos estudiosos, algo que, felizmente, tem mudado nos últimos anos. Entretanto, parece ainda predominar a concepção de que os africanos escravizados, uma vez no cativeiro, abandonavam suas línguas em direção ao português.

Após questionar essa visão tradicional, mostramos que alguns dos trabalhos que se ocuparam do estudo da LGM, uma língua africana da diáspora, concluíram que ela seria uma variedade em fase de reestruturação, por assim dizer, acentuada, uma variedade em fase de crioulização, para Yai (1997), e uma variedade em fase de pidginização, para Bonvini (2008). Entretanto, conforme argumentamos, a análise da sintaxe da LGM no contexto da sintaxe das línguas Gbe mostra que a variedade documentada por Costa Peixoto se aproxima muito de suas "irmãs" africanas.

Com efeito, tal qual debatemos em Santos da Silva (2020), a LGM apresenta uma série de mudanças em relação ao Gbe diacrônico e às línguas Gbe modernas, fato explicável pela complexa ecologia de contato linguístico na qual ela estava imersa. Porém, tais mudanças não fazem dela uma língua extremamente distante das demais línguas Gbe, mas apenas uma variedade Gbe um pouco mais diferente, diante da tamanha homogeneidade lexical e morfossintática que caracteriza esse grupo.

Por fim, defendemos que, para além da compreensão da sintaxe da LGM como uma língua Gbe da diáspora, com suas permanências e mudanças, esse tipo de análise é relevante até mesmo para a compreensão do desenvolvimento do $\mathrm{PB}$, uma vez que, ao conhecer a gramática da LGM, conheceremos um pouco mais da gramática de uma das línguas que, na ecologia de contato do Brasil colonial, contribuíram para a emergência do PB como hoje o conhecemos. 
- A sintaxe da língua geral de Mina no contexto da sintaxe das línguas Gbe: problematizando hipóteses de reestruturação

\section{Referências}

$\mathrm{ABOH}, \mathrm{E}$. O. A 'mini' relative clause analysis for reduplicated attributive adjectives. Linguistics in the Netherlands, v. 24, p. 1-13, 2007.

$\mathrm{ABOH}, \mathrm{E}$. O. Clause structures and Verb series. Linguistic Inquiry, v. 40, n. 1, p. 1-33, 2009.

$\mathrm{ABOH}, \mathrm{E}$. O. The Emergence of Hybrid Grammars: Language Contact and Change. Cambridge: Cambridge University Press, 2015a.

$\mathrm{ABOH}, \mathrm{E}$. O. Functional verbs in Gungbe: The case of inherent complement verbs.

Linguística: revista de estudos linguísticos da Universidade do Porto, v. 10, p. 9-29, 2015b.

$\mathrm{ABOH}$, E. O.; ESSEGBEY, J. General properties of the clause. In: ABOH, E. O.; ESSEGBEY, J. (ed.). Topics in Kwa Syntax. London: Springer, 2010. p. 39-64.

AMEKA, F. Information Packaging Constructions in Kwa. In: ABOH, E. O.; ESSEGBEY, J. (ed.). Topics in Kwa Syntax. London: Springer, 2010. p. 141-175.

ARAÚJO, F. Fome do ouro e fama da obra. Antonio da Costa Peixoto e a "Obra Nova de Lingoa Geral de Mina" - alianças, proximidades e distâncias de um escritor português no Brasil colonial do século XVIII, 2013. No prelo.

AWOYALE, Y. Complex Predicates and Verb Serialization. University of Ilorin and MIT, Cambridge, Massachusetts, 1988.

BONVINI, E. Línguas africanas e português falado no Brasil. In: FIORIN, J. L.; PETTER, M. M. T. (org.). África no Brasil: a formação da língua portuguesa. São Paulo: Contexto, 2008.

CASTRO, Y. P. A Língua Mina-Jeje no Brasil: um falar africano em Ouro Preto no século XVIII. Belo Horizonte: Fundação João Pinheiro; Secretaria de Estado da Cultura, 2002.

CASTRO, Y. P. De como Legba tornou-se interlocutor dos deuses e dos homens.

Cadernos Pós Ciências Sociais, São Luís, v. 1, n. 2, p. 123-133, 2004.

ESSEGBEY, J. Inherent complement verbs revisited: towards an understanding of argument structure constructions in Ewe. Nijmegen: MPI Dissertation series 10, 1999. 
FERNANDES, G. A língua geral de Mina (1731/1741) de António da Costa Peixoto.

Confluência, v. 43, n. 2, p. 28-46, 2012.

LEFEBVRE, C.; BROUSSEAU, A. M. A grammar of Fongbe. Berlin/New York: Mouton, 2002.

LOPES, E. C. Os trabalhos de Costa Peixoto e a língua Evoe no Brasil. In: SILVEIRA, L. Obra Nova de língua geral de Mina, de António da Costa Peixoto. Agência Geral das Colônias: Lisboa, 1945.

MANESSY, G. Créoles, pidgins, variétés véhiculaires, procès et genèse. Paris: Editions du CNRS, 1995.

MUFWENE, S. S. Language Evolution: contact, competition and change. London: Continuum, 2008.

PARÉS, L. N. Os Africanos Ocidentais. In: SCHWARCZ, L.; GOMES, F. (org.). Dicionário Escravidão e Liberdade: 50 textos críticos. São Paulo: Companhia das Letras, 2018.

ROSA, M. C. O quimbundo em cinco testemunhos gramaticais. Confluência, v. 1, n. 56, p. 55-113, 2019.

SANTOS DA SILVA, W. A língua geral de Mina e o Ciclo do Ouro: um capítulo da história dos contatos no Brasil. 2020. Tese (Doutorado em Linguística) - Faculdade de Filosofia, Letras e Ciências Humanas, Universidade de São Paulo, São Paulo, 2020.

SANTOS DA SILVA, W. Estudando a sintaxe da língua geral de Mina: as línguas Gbe e a formação do Português Brasileiro. In: CONSTELAÇÕES DIACRÔNICAS EM HOMENAGEM A CHARLOTTE GALVES E MARY KATO. V CONGRESSO INTERNACIONAL DE LINGUÍSTICA HISTÓRICA, 2021, Campinas: Unicamp, 2021.

SOARES, M. C. Diálogos Makii de Francisco Alves de Souza: manuscrito de uma congregação católica de africanos Mina, 1786. São Paulo: Editora Chão, 2019.

SOUZA, L. M. Desclassificados do ouro: a pobreza mineira no século XVIII. 4. ed. Rio de Janeiro: Graal, 2004. 
- A sintaxe da língua geral de Mina no contexto da sintaxe das línguas Gbe: problematizando hipóteses de reestruturação

TEIXEIRA DE SOUSA, L. Sobre as origens da distinção entre negação de proposição e negação de evento no português brasileiro. Estudos de linguística galega, v. esp. I, p. 123-138, 2018.

YAI, O. B. Identifying Enslaved Africans in Fon and Yoruba Vocabularies in Brazil (18th-19th centuries). In: LOVEJOY, P. E. Identifying enslaved Africans in the nigerian hinterland. Toronto: Unesco Conference, 1997. p. 543-553.

COMO CITAR ESTE ARTIGO: SILVA, Wellington Santos da. A sintaxe da língua geral de Mina no contexto da sintaxe das línguas Gbe: problematizando hipóteses de reestruturação. Revista do GEL, v. 18, n. 3, p. 169-190, 2021. Disponível em: https://revistadogel.gel.org.br/

Submetido em: 13/09/2021 | Aceito em: 05/11/2021. 